\title{
POLLINATION EFFECTIVENESS OF SPECIALIST AND GENERALIST VISITORS TO A NORTH CAROLINA POPULATION OF CLAYTONIA VIRGINICA ${ }^{1}$
}

\author{
Alexander F. Motten, Diane R. Campbell, and David E. Alexander \\ Department of Zoology, Duke University, Durham, North Carolina 27706 USA \\ AND \\ Helen L. Miller \\ Department of Botany, Duke University, Durham, North Carolina 27706 USA
}

\begin{abstract}
We measured the pollination effectiveness and visitation rates of major insect visitors of Claytonia virginica, an obligately insect-pollinated spring wildflower, in a North Carolina deciduous forest. Seed set in the population was not pollinator-limited except during rainy weather and very early in the flowering season. The solitary bee Andrena erigeniae and the bee fly Bombylius major were responsible for more than $75 \%$ of the visits to $C$. virginica. Andrena erigeniae is a specialist on $C$. virginic $a$, while $B$. major is a common visitor to many plant species. We measured the effectiveness of a pollinator by the probability that a visit resulted in fruit (capsule) formation. For those flowers that were successfully pollinated and thus produced a capsule, number of seeds did not vary with visitor identity or the total number of visits received. Although B. major and female $A$. erigeniae differ greatly in morphology and foraging behavior, a visit by either insect results in equally high seed set. As B. major is about two-thirds as abundant as A. erigeniae females on $C$. virginica, both insects contribute substantially to seed set in our population. With the visitation frequency and pollination effectiveness we measured, the generalist $B$. major alone has the potential to pollinate three-quarters of the flowers.
\end{abstract}

Key words: Andrena erigeniae; Bombylius major; Claytonia virginica; North Carolina; pollination; reproductive success; seed set; spring wildflower.

\section{INTRODUCTION}

Insufficient transfer of pollen to receptive stigmas is one factor that has been proposed as a cause of low seed set in natural plant populations (e.g., Kevan 1972, Reader 1975, Waser 1978 and 1979, Zimmerman 1980). In a population of animal-pollinated plants, fertilization of all the ovules physiologically capable of developing into seeds can result from the pollinating activity of one abundant floral visitor species or from the combined services of several visitor species. The contribution to a plant's reproductive success that each type of visitor makes is determined by both its visitation rate and by its pollination effectiveness: the seed set resulting from a single visit (Beattie 1972). Pollination effectiveness could be affected by the degree of floral preference of the visitor. A specialist visitor, one that visits only one host species and is morphologically or behaviorally specialized to gather nectar or pollen from that species, may be a more effective pollinator than a generalist visitor, one that feeds at flowers of many plant species. For example, while visiting several different species, a generalist may lose some of the pollen grains picked up from one species during subsequent visits to another species. Deposits of heterospecific pollen may also interfere with the germination of conspecific pollen grains in

${ }^{1}$ Manuscript received 17 July 1980; revised 27 February 1981; accepted 28 February 1981. some species (Waser 1978, Brown and Kodric-Brown 1979). Even if floral distribution constrains a generalist to visit the flowers of a single species, the generalist may transfer fewer pollen grains per visit than a specialist which is better suited behaviorally or morphologically to that flower. Many zoophilous flowers attract a variety of floral visitors that differ in degree of host preference (Grant and Grant 1965, Baker and Hurd 1968). In this study we compared the pollination effectiveness of generalist and specialist visitors to Claytonia virginica L. (Portulacaceae), a common wildflower of the eastern North American deciduous forests. Claytonia virginica (spring beauty) blooms in early spring when seed set may be limited by pollinator availability and when flower species may compete for pollination (Schemske et al. 1978). We used effectiveness measurements and observations of pollinator visitation rates and foraging behavior to determine whether seed set in a $C$. virginica population was pollinator-limited, and to compare the contribution of a specialist and generalist visitor to the plant's reproductive success.

Traditionally, pollination biologists have used indirect methods to estimate the effectiveness of flower visitors as pollinators of a particular plant. As reviewed by Cruden (in Baker and Hurd 1968), the techniques include analysis of the identity, placement, and quantity of pollen grains on a visitor's body and careful observation or cinematography (Macior 1967) of 
visitor foraging behavior. Several workers (e.g., Bohart and Nye 1960, Ehrenfeld 1979, Linsey 1979) have combined data of these kinds with estimates of visitor abundance or activity to create index values to rank visitors according to pollination effectiveness. Other workers have supplemented behavioral observation of flower visitors with examination of the pollen loads they deposit on a receptive stigma (e.g., Beattie 1971, Levin and Berube 1972, Ornduff 1975). Primack and Silander $(1975,1978)$ have extended this technique by comparing the number of pollen grains that two insect pollinators of Oenothera deposit on a stigma during a single visit, and then correlating stigma loads with seed set in greenhouse experiments.

We quantified pollinator effectiveness with a more direct approach by measuring seed set in the field as a function of the number of pollinator visits. This technique has been applied in agriculture to judge the frequency of honeybee visits necessary to achieve full crop pollination (e.g., Adlerz 1966). To our knowledge, it has not been used to compare pollinator effectiveness within the more diverse pollinator fauna of a natural community. Using seed set as a unit of measure has the advantage of describing the effectiveness of a flower visitor operationally, in terms of the plant's reproductive success. Thus, pollinators with different morphologies or foraging behaviors can be compared directly. By measuring seed set rather than counting pollen grains on stigmas we avoided biases resulting from qualitative differences in the viability or compatibility of the pollen carried by different visitors.

\section{Methods}

\section{Study sites}

We conducted this study on two populations of $C$. virginica growing in mesic, lowland deciduous forest in the Piedmont region of North Carolina. Preliminary estimates of pollinator effectiveness were made in 1978 in the Korstian Division of Duke Forest, Orange County, North Carolina. We made detailed effectiveness experiments and measurements of reproductive success in 1979 in the Oosting Natural Area of Duke Forest, about $8 \mathrm{~km}$ west of the Korstian Division site and $12 \mathrm{~km}$ north of Chapel Hill, North Carolina. We collected insects, observed floral biology, and measured insect visitation rates at each locality. At both sites the common overstory trees were Liriodendron tulipifera, Liquidambar styraciflua, Fagus grandifol$i a$, and Acer rubrum. Vernal herb associations in the two areas also corresponded closely, with dominants including Erythronium umbilicatum $(=E$. americanum see Parks and Hardin 1963; all other North Carolina nomenclature follows Radford et al. 1968), $\mathrm{He}$ patica americana, Stellaria pubera, Thalictrum thalictroides, and Tiarella cordifolia. Plant assemblages in the Oosting Natural Area have been described by Bornkamm (1975). Populations of $C$. vir- ginica were extensive at both sites, covering more than $500 \mathrm{~m}^{2}$, with at least 100 flowers $/ \mathrm{m}^{2}$ in the densest areas during the period of peak bloom.

\section{Floral biology}

In North Carolina, a typical raceme of $C$. virginic $a$ bears 6 to 15 flowers that open 1 or 2 at a time over a period of about $2 \mathrm{wk}$. Flowers are protandrous. On the 1st $d$ that a flower opens, the five erect anthers dehisce and surround the pistil. On subsequent days the stamens reflex against the petals, and the three stigmatic lobes unfold. Receptive (pistillate) flowers are thus easily recognized. Flowers are usually pistillate for $1 \mathrm{~d}$, but if unpollinated may persist up to $6 \mathrm{~d}$ before withering. On warm, sunny days flowers are open about 4 or $5 \mathrm{~h}$ from midmorning to early afternoon. The petals are tightly furled at night and during rainy weather. Nectar is secreted at the base of the petals and is easily accessible in the dish-shaped corolla of the open flower. We measured nectar sugar contents using the sulfuric acid-phenol colorimetric analysis (Damm 1966). Analyses were performed on $1 \mathrm{~mL}$ distilled water washings of flowers caged for 24 or $48 \mathrm{~h}$. Two-day-old (hence pistillate) flowers contained nearly twice the sugar of 1-d-old (staminate) flowers, indicating approximately equal rates of nectar production in staminate and pistillate flowers.

On the basis of field and greenhouse insect exclusion and hand-pollination experiments, we concluded that plants in our $C$. virginica populations are self-compatible but not self-pollinating and therefore require insect pollination. Schemske (1977) obtained the same results in Illinois, although Lovell (1942) reported facultative self-pollination in Kentucky plants. In most respects the floral biology of our $C$. virginica populations is quite similar to that of Schemske's, although his plants are from a diploid race, and ours are most likely from a triploid one (Lewis and Semple 1977).

\section{Insect visitors}

Claytonia virginica is typical of a great number of species with a "bee and long-tongued fly" or "promiscuous pollination" syndrome (Grant 1948). The two most common insect visitors to $C$. virginica in Piedmont North Carolina are a solitary bee, Andrena (Ptilandrena) erigeniae Robertson, and the bee fly, Bombylius major L. Andrena erigeniae is virtually monolectic on C. virginica (Davis and LaBerge 1975) or the closely related $C$. caroliniana. Females visit the flowers for nectar and pollen. During a visit, a female usually brushes against each anther and contacts the stigma. The males, which are smaller than females, visit $C$. virginica to search for mates and nectar. Robertson (1930) concluded that both sexes of $A$. erigeniae emerge simultaneously, but in our area the males appear on $C$. virginica flowers several days to a week before the females. Bombylius major is a widely distributed, generalist flower visitor whose sexes we 
TABLE 1. List of insect visitors to $C$. virginica.

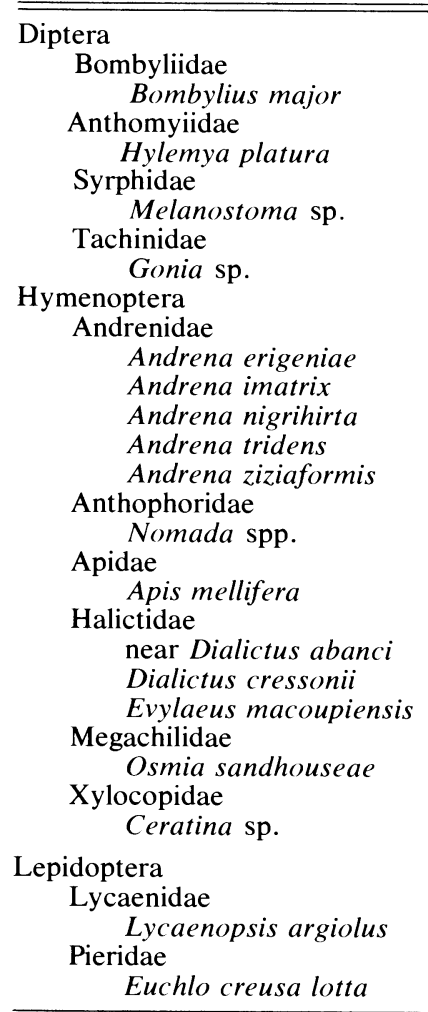

could not distinguish in the field. It freely visits many species on our study sites and shows no preference among Hepatica americana, Thalictrum thalictroides, Stellaria pubera, Cardamine angustata, and C. virginica (A. F. Motten et al., personal observations). Using its long proboscis it takes nectar and occasionally pollen grains while hovering over the flowers. Bombylius major and A. erigeniae males make shorter visits and less extensive contact with the reproductive parts of the flower than do A. erigeniae females. Bombylius major and $A$. erigeniae females accounted for $>75 \%$ of the visits we observed to $C$. virginica. Additional, much less common visitors, primarily nectar foragers, are shown in Table 1. Robertson (1929) and Schemske (1977) have compiled similarly diverse lists of flower visitors to $C$. virginica.

\section{Experiments and observations}

We measured pollinator effectiveness in $0.5-1.0 \mathrm{~m}^{2}$ plots of $C$. virginica. Except during periods of observations of floral visitors, the plants were enclosed in insect-proof cages constructed of aluminum window screen and fine-mesh nylon net. We removed the cages during pollinator visitation periods for intervals of 20 min to several hours depending on pollinator activity and flower density. We numbered each flower individually and noted its developmental stage, pistillate or staminate. For each insect entering the plot we re- corded in sequence the numbers of all flowers visited. We then recaged the plots until all flowers open during the observation interval had withered. About $10 \mathrm{~d}$ after an experiment we checked the flowers for capsule development and counted the seeds. Virtually all $C$. virginica flowers contain six ovules. At least one of the ovules must develop into a seed for a capsule to be produced. Seed set and capsule formation data used to calculate pollinator effectiveness were collected from 245 pistillate flowers visited a total of 585 times. The most common pollinators, $A$. erigeniae females and $B$. major, accounted for $83 \%$ of these visits. We were able to obtain data for flowers visited by either $A$. erigeniae females or B. major alone by taking advantage of the temporal difference in their flight periods. The bees are most active in the morning and usually cease foraging by afternoon when the supply of easily collected pollen from the newly opened flowers has been depleted (Davis and LaBerge 1975). The nectar-gathering bee flies are more active on $C$. virginica in the afternoon.

Visitation rate estimates were obtained in part from data collected during the effectiveness experiments. More detailed measurements were made in 1978 on four $2 \times 2 \mathrm{~m}^{2}$ plots. We watched each plot for $20 \mathrm{~min}$ in both the morning and the afternoon on three warm, sunny days during the peak $C$. virginica blooming period. Plots with flower densities above and below the population average were included, with a mean fourfold difference between high- and low-density plots. In addition, we measured visitation rates throughout the 1978 and 1979 seasons on plots of various sizes scattered in the study sites. Lengths of observation periods ranged from $20 \mathrm{~min}$ to $1.5 \mathrm{~h}$, depending on insect activity and the density of plants in bloom. The total observation time was $41 \mathrm{~h}$. We standardized visitation records in units of visits per flower per hour to account for differences in number of flowers watched and in duration of observations.

We estimated seed set as a function of flowering time in the Natural Area population as a whole by monitoring the performance of flowers on 50 racemes in two control plots with unlimited insect access. To obtain adequate sample sizes for flowers opening late in the season we expanded these plots to include very late-flowering racemes no more than $2 \mathrm{~m}$ away. To obtain more data on early-blooming flowers we constructed a third plot composed of 15 transplanted plants whose blooming had been forced in a greenhouse. Racemes were checked at least every other day for opening and senescence of flowers and for capsule development. Seeds that were misshapen or not fully developed were counted as aborted ovules. The period of peak bloom of the population was estimated subjectively using the method of Anderson and Hubricht (1940), and by recording at 2-d intervals throughout the season the maximum number of flowers within a $1.0-\mathrm{m}^{2}$ area. 

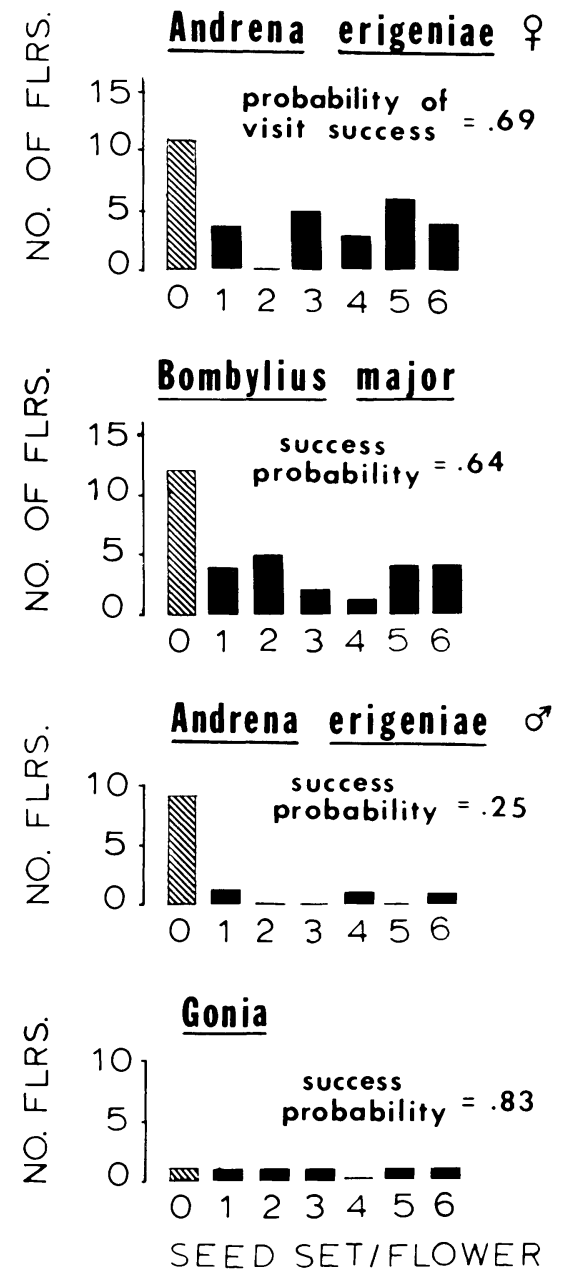

FIG. 1. Distribution of seed set in C. virginica flowers visited once by various insects. Probability of visit success (proportion of flowers that set seed) is also shown for each insect. For $A$. erigeniae females and $B$. major this value is higher than that calculated from the graphs as it includes flowers that produced capsules whose actual seed set could not be determined.

\section{RESUlts}

\section{Measurement of pollination effectiveness}

The most direct means of evaluating visitor effectiveness is to examine seed set resulting from a single visit. Frequency distributions of seed set for all insects for which single-visit data were obtained are shown in Fig. 1. All four visitors for which we obtained effectiveness data, male and female A. erigeniae, B. major, and the tachinid fly Gonia, can successfully pollinate C. virginica. A successful visit is defined as one in which a capsule is produced. Note that the most common specialist visitor, female $A$. erigeniae, and the most common generalist, B. major, have similar probabilities of visit success, 0.69 and 0.64 , respectively. Sample sizes for $A$. erigeniae males and Gonia are
TABLE 2. The effect of number of visits and insect type on seed set per capsule.

a) Mean seed set per capsule by visit number and visitor identity.

Sample sizes are shown in parentheses.

Seeds/capsule

\begin{tabular}{cccc}
\cline { 2 - 4 } No. of visits & $\begin{array}{c}\text { Andrena } \\
\text { erigeniae } \\
\text { females }\end{array}$ & $\begin{array}{c}\text { Andrena } \\
\text { Bombylius } \\
\text { major }\end{array}$ & $\begin{array}{c}\text { erigeniae } \\
\text { males and } \\
\text { Gonia }\end{array}$ \\
\hline 1 & 4.00 & 3.40 & 3.50 \\
$>1$ & $(21)$ & $(20)$ & $(8)$ \\
& 4.53 & 3.89 & 4.30 \\
& $(15)$ & $(28)$ & $(10)$
\end{tabular}

95\% confidence interval for the difference in seed set: between singly and multiply visited flowers $-0.12,1.34$ between flowers visited by $A$. erigeniae

females and those visited by other insects $-0.24,1.22$

b) Analysis of variance table.

For this unbalanced ANOVA, we reported only the mean squares used to test the null hypothesis that the unweighted cell means are equal.

\begin{tabular}{lrrrrr}
\multicolumn{1}{c}{ Source } & df & MS & $F$ & $P$ & \\
\hline Insect & 2 & 7.696 & 1.35 & 0.264 NS \\
Number of visits & 1 & 7.847 & 2.76 & $0.100 \mathrm{NS}$ \\
Insect $\times$ number of visits & 2 & 0.315 & 0.06 & $0.946 \mathrm{NS}$ \\
Error & 96 & 2.847 & & & \\
\hline
\end{tabular}

smaller than for the other pollinators not only because these insects were less abundant overall, but also because they were most common earlier in the blooming season when floral densities were low. Later in the season, flowers visited by $A$. erigeniae males and Gonia were usually visited first by the more abundant $A$. erigeniae females and $B$. major. The paucity of single-visit data for Gonia and A. erigeniae males precludes statistical comparison of the pollination effectiveness of these insects with that of $A$. erigeniae females and $B$. major. Nevertheless, the results indicate that even the less common visitors can still make measurable contributions to seed set in $C$. virginica.

Most flowers of $C$. virginica receive many visits, usually from more than one type of insect. In order to compare the pollination effectiveness of $A$. erigeniae females and $B$. major statistically, we used data from flowers visited repeatedly by one or both of these insects as well as from flowers visited just once by either of them. These results were incorporated in a model in which we equated effectiveness with the probability that a visit was successful, i.e., resulted in capsule formation. As indicated by a two-way analysis of variance on seed set per capsule in successfully visited flowers, probability of capsule formation is a sufficient measure of pollination effectiveness in $C$. virginica (Table 2). There was no significant increase in seed set per capsule with additional visits, even though all flowers visited more than once, including ones visited 
TABLE 3. The probability that a visit results in successful pollination for each insect species and type of flower last visited. For an explanation of how the probability values were obtained and a description of statistical method used, see text.

\begin{tabular}{ccc}
\hline \hline & $\begin{array}{c}\text { Probability } \\
\text { of }\end{array}$ & $\begin{array}{c}\text { Num- } \\
\text { capsule }\end{array}$ \\
Visit type & formation & its \\
\hline
\end{tabular}

1. Visit by A. erigeniae female from staminate flower.

2. Visit by A erigeniae female from pistillate flower.

$\begin{array}{cc}p=0.68 & 32 \\ p_{2}=0.60 & 27 \\ p_{3}=0.75 & 43 \\ p_{4}=0.26^{*} & 40\end{array}$

3. Visit by B. major from staminate flower.

4. Visit by B. major from pistillate flower.

Combined estimate for visit types 1-3 as calculated under the constraint $p_{1}=p_{2}=p_{3}^{\dagger}$ $p_{c}=0.69$

* This value is significantly different at the $p<.05$ level from each of the other three parameters. $p_{1}, p_{2}$, and $p_{3}$ are not significantly different from each other.

$\dagger$ The combined estimate was determined from $p_{1}, p_{2}$, and $p_{3}$ only, as many of the data used to calculate $p_{4}$ represented long series of sequential visits to pistillate flowers in plots where the proportion of pistillate to staminate flowers exceeded that found in the natural population.

five or six times, were analyzed in a single category. Type of pollinator also had no significant effect on the number of seeds produced per capsule. Although seed set per capsule did not increase significantly with increased visit number, there was a significant increase in the proportion of flowers producing capsules $(2 \times$ 4 contingency test, $G=14.62, P<.005$ ).

Our model allows estimation and comparison of the pollination effectiveness of the generalist, B. major, and the specialist, female $A$. erigeniae, depending on the developmental stage of the last flower visited by each insect. The probability of visit success may depend on whether the insect last visited a staminate flower, where it could have picked up pollen, or a pistillate (receptive) flower, where it may have deposited some of its pollen. A large reduction in mean visit success following a visit to a pistillate rather than a staminate flower indicates low pollen carry-over. The model includes four parameters:

$p_{1}=$ probability that a visit by an $A$. erigeniae female from a staminate flower results in capsule formation;

$p_{2}=$ probability that a visit by an A. erigeniae female from a pistillate flower results in capsule formation;

$p_{3}=$ probability that a visit by $B$. major from a staminate flower results in capsule formation;

$p_{4}=$ probability that a visit by $B$. major from a pistillate flower results in capsule formation.

The probability that a flower that received only one type of visit does not produce a capsule is equal to $(1-p)^{n}$, where $p$ equals the probability that a single visit results in capsule formation, and $n$ equals the number of visits. Each flower included in the analysis could have received up to four different kinds of visits, and we have no reason to think that the probability that a given type of visit will result in capsule formation depends on the types of visits already received. Hence the probability that the $i^{\text {th }}$ flower does not produce a capsule, $P\left(Y_{i}=0\right)$, is equal to $\left(1-p_{1}\right)^{n_{i 1}}$ $\left(1-p_{2}\right)^{n_{i 2}}\left(1-p_{3}\right)^{n_{i 3}}\left(1-p_{4}\right)^{n_{i 4}}$, where $n_{i j}$ is equal to the number of visits of type $j$ to the $i^{\text {th }}$ flower. The probability that the $i^{\text {th }}$ flower does produce a capsule is equal to $1-P\left(Y_{i}=0\right)$.

We estimated the four parameters by the maximumlikelihood method (Table 3; see Mood et al. 1974 for a detailed description of likelihood estimation). Then, for each pair of parameters we tested the null hypothesis that the two parameters are equal. The generalized likelihood ratio, $\lambda$ (lambda), is the maximum value of the likelihood function under the constraints specified by the null hypothesis divided by the maximum value of the likelihood function when all parameters are free to vary. The quantity $-2 \ln \lambda$ is approximately distributed as a chi-square variate. As a conservative measure in performing these multiple comparison tests, we compared each value of $-2 \ln$ $\lambda$ with $\chi^{2}$ with three degrees of freedom, the number for the overall null hypothesis that all of the parameters are equal. There were no significant differences between the probability of a successful visit by an $A$. erigeniae female following a visit to a staminate flower, A. erigeniae female from a pistillate flower, and B. major from a staminate flower. However, the probability of a successful visit by $B$. major following a visit to a pistillate flower was significantly less than each of the other three parameters $(P<.05$; Table 3$)$. The estimate of this parameter is only $38 \%$ as great as the combined estimate for the other three parameters, 0.69 .

\section{Visitation rates of Andrena erigeniae females and Bombylius major}

A pollinator's contribution to seed set is determined not only by its pollination effectiveness for a single flower but also by its visitation rate in the population at large. Because the bees and flies exhibit temporal preferences in their flight times, we calculated each species' activity on $C$. virginica on a daily rather than hourly basis. The flowers are generally open for about $2 \mathrm{~h}$ in the morning and $2 \mathrm{~h}$ in the afternoon. From separate estimates of visitation rates during morning and afternoon (Table 4), and assuming $2 \mathrm{~h}$ of visits for both periods, we estimated a daily total rate of 4.1 bee visits and 2.4 fly visits per flower. The measurements in Table 4 were made on ideal days for pollination, warm and sunny weather with the $C$. virginica population in full bloom. Fly visits may be slightly under- 
TABLE 4. Diurnal pattern of mean visits per flower per hour on 6, 8, and 9 April 1978. Number of flowers per plot ranged from 24 to 215 . $N=$ twelve 20 -min observation intervals for each time and species.

\begin{tabular}{lcc}
\hline & Morning & Afternoon \\
\hline A. erigeniae & $1.48(s=1.12)$ & $0.59(s=0.59)$ \\
B. major & $0.51(s=0.47)$ & $0.71(s=0.58)$ \\
\hline
\end{tabular}

represented as B. major continued to visit later-closing flowers in the population and thus remained active longer than $2 \mathrm{~h}$ in the afternoon. Over the entire season, fly visits may also be proportionately more numerous since $B$. major begins visiting flowers earlier in the year than the $A$. erigeniae females.

In terms of visits to receptive flowers, the numerical superiority of the bees is further diminished by a preference for staminate over pistillate flowers. For bees that visited 10 or more flowers the percentage of visits to staminate flowers was much higher than the percentage of flowers in the plot that were staminate (Wilcoxon matched-pairs signed-ranks test, $T=6$, $P<.01, N=13$ ). The percentage of visits by flies to staminate flowers was slightly higher than expected, but the difference was not significant (Wilcoxon test, $T=17, P>.05, N=10$ ). When the overall visitation rates are adjusted for preference, the estimated daily numbers of bee and fly visits per receptive flower are 3.0 and 2.1 , respectively.

\section{Total visitation rates in the population}

The total visitation rate ranged between 1 and $>2$ visits $\cdot$ flower ${ }^{-1} \cdot \mathrm{h}^{-1}$ during most of the main blooming season (Fig. 2c). This hourly rate corresponds to $4-8$ visits/d. Early in the year when floral density was low (Fig. 2a), before the 19 March appearance of $A$. erigeniae and B. major (Fig. 2b), total insect visitation rates were lower than during the peak blooming season. Gonia flies and Nomada bees were the principal visitors at that time. However, most of our subsequent estimates of visitation rates fall within the standard errors of the visitation rates on 6, 8, and 9 April 1978 (Fig. 2c). On each of these days we made especially comprehensive measurements of visitation rates; each of two plots with low floral density and each of two plots with high floral density were observed for $20 \mathrm{~min}$ during the morning and for $20 \mathrm{~min}$ more during the afternoon. The reduced visitation on 24-26 March and on 3-4 April coincided with heavy rains, when most C. virginica flowers were closed and insect flight activity was curtailed. In the interval from 18 March, when $A$. erigeniae males and B. major appeared, until 27 March, when $A$. erigeniae females appeared, the $A$. erigeniae males accounted for over half of the observed visits. After 27 March, A. erigeniae females and $B$. major together accounted for the great majority of the visits, with the percentage for all other visitors
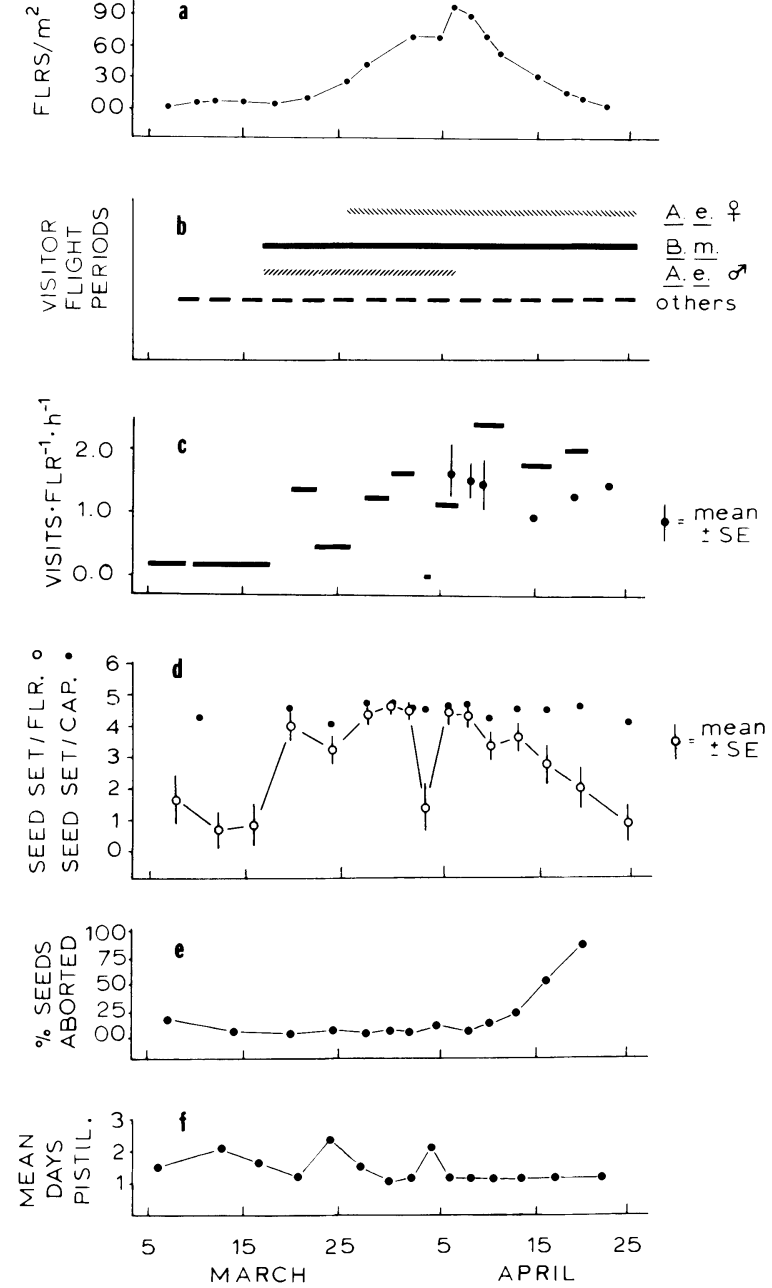

Fig. 2. Flowering phenology, pollinator activity, seed set characteristics, and floral persistence during the 1979 C. virginica blooming season. (a) Maximum number of flowers in the densest square metre of the 1979 Natural Area population. (b) Dates of insect activity on C. virginica. (c) Mean visitation rate for all insect visitors. For the 1979 measurements, dates are grouped in intervals that coincided with the appearance of important pollinators and spells of rainy weather. When pollinators were very abundant the intervals spanned no more than $3 \mathrm{~d}$. Horizontal bars indicate the actual dates included. Data from 1978 (dots) are shown for comparison; each dot represents the average of several measurements from a single day. (d) Mean seed set per flower for all flowers in control plots and mean seed set per capsule for all flowers that produced at least one seed. For the 1st $2 \mathrm{wk}$ and the last $10 \mathrm{~d}$ of the season, each circle represents data from a 5-d period; all other circles represent 2- or 3-d periods. At least 10 flowers are included in each mean. Flowers were assigned to a given interval on the basis of the last day they were pistillate, which was their final opportunity to be pollinated. (e) The percentage of all seeds harvested during the sampling interval that showed obvious sign of aborted development. (f) Mean duration of pistillate stage. Flowers were assigned to sampling intervals according to their first day pistillate. For (e) and (f), the symbols are graphed at the midpoints of the sampling intervals. 
combined declining from $23 \%$ on 29 March to only about $3 \%$ by 20 April.

\section{Pollination success in the population}

Measurements of visitation rate and pollination effectiveness can be combined to estimate the likelihood that a flower will be successfully pollinated, thus providing an indication of pollination success in the population as a whole. Although other visitors besides $A$. erigeniae females and $B$. major are also effective $C$. virginica pollinators (Fig. 1) and may contribute significantly to pollination early in the year, they are responsible for only a very small proportion of visits during the main blooming season. We calculated the probability that a flower will be successfully pollinated by $A$. erigeniae females and $B$. major alone using the pooled effectiveness value for these pollinators $\left(p_{c}=\right.$ 0.69 , Table 3 ) and our earlier determination of their combined mean visitation rate (5.1 visits receptive flower ${ }^{-1} \cdot \mathrm{d}^{-1}$ ). Assuming that a flower remains pistillate for just $1 \mathrm{~d}$ and that its probability of being visited is independent of previously received visits (i.e., the number of visits received by a flower follows a Poisson distribution), the probability of successful pollination by bees and flies alone is 0.97 . During the period 29 March to 2 April, when visitation rates exceeded 4 visits/d, 87 out of 88 control flowers produced capsules.

\section{Seed set in the population}

Throughout the season, mean seed set per capsule remained very close to 4.5 regardless of pollinator availability or activity (Fig. 2d). In contrast, mean seed set per flower, a value that includes those flowers that produced no capsule at all, varied considerably. Low values are due to failures in capsule formation (seed set per flower $=0$ ) rather than a reduction in the number of seeds per capsule. An increasing failure of ovules to develop into seed (Fig. 2e) probably accounts for the decline in seed set per flower later in the season.

Variable capacities of individual racemes to mature fertilized ovules could account for a mean seed set per capsule below the maximum six possible. The number of seeds per capsule was compared using an analysis of covariance to test for differences among 44 racemes from the control plots. The covariate used was last date of flowering. There was a highly significant $(P<.001)$ difference among racemes, which could be due either to microenvironmental or genetic differences, independent of flowering dates. Thus, even with the high level of pollination in midseason, many flowers of some racemes failed to mature six ovules. This reinforces our earlier conclusion that a single successful $A$. erigeniae female or $B$. major visit can account for nearly all of a typical flower's seed output.

\section{Discussion}

\section{Pollinator limitations on seed set} in $\mathrm{C}$. virginica

Measurements of the pollination effectiveness and visitation frequency of the two most abundant visitors, $A$. erigeniae and $B$. major, indicate that seed set in our C. virginica population is generally not pollinatorlimited during the main blooming season. Our data indicate that female $A$. erigeniae and B. major alone can pollinate $97 \%$ of the flowers. In fact only early in the season when few plants were in bloom (Fig. 2a) and during two pronounced periods of rainy weather, 24-26 March and 3-4 April, did we observe some flowers that remained unpollinated. Insect activity was low at these times (Fig. 2c). That few flowers remained unpollinated for more than a day is also indicated by the mean duration of the pistillate stage in our population of $1.3 \mathrm{~d}$. The values $>1 \mathrm{~d}$ occur early in the season or during the two rainy spells (Fig. 2f). In contrast, in the Illinois $C$. virginica populations studied by Schemske et al. (1978) the mean duration of the pistillate stage was $\approx 2 \mathrm{~d}$, suggesting the plants may have been infrequently pollinated. Schemske et al. recorded total insect visitation rates $\leqslant 2.5$ visits. flower ${ }^{-1} \cdot \mathrm{d}^{-1}$, far lower than the rates we observed for A. erigeniae females alone. B. major did not occur in their Illinois woods, and the lack of sufficient numbers of alternative pollinators to supplement A. erigeniae may account in part for the generally lower seed set they observed.

The decline in seed set per flower and the increase in the percentage of aborted ovules late in the blooming season (Fig. 2d and 2e) are not correlated with insect visitation frequency, which remained high enough to achieve full pollination (Fig. 2c), but they are correlated with falling light levels during canopy closure. Schemske (1977) also noted a pattern of progressively greater ovule abortion during the $1 \mathrm{st}$ yr of his study and attributed it to decreasing light availability.

\section{Factors promoting enhanced pollination}

Heinrich and Raven (1972) have hypothesized that zoophilous plants promote outcrossing in one of two ways: (1) by attracting the exclusive services of specialist pollinators, or (2) by relying on an adequate frequency of successful visits regardless of pollinator preference. The principal factor responsible for a high level of seed set in our C. virginica population is a sufficient number of visits by a combination of suitable insects. All four of the most common visitors shown in Fig. 1 successfully pollinate C. virginica. Species with diverse foraging behaviors are effective pollinators; the central position of the anthers and receptive stigma permits pollination by large insects that land in the middle of the flower (e.g., A. erigeniae females, 
Gonia), smaller ones that crawl over the stamens and pistil in search of nectar (e.g., A. erigeniae males), or hovering species that brush against anthers and stigma (B. major). The inquiline bee Nomada, which is similar in size, pubescence, and foraging behavior to $A$. erigeniae males, may also pollinate $C$. virginica.

Successful pollination by visitors other than specialists may be a feature common to many flowers that attract a diverse group of pollinators; the contribution of each pollinator is then determined primarily by its abundance (Beattie 1971, 1972). Our seed set measurements have certainly shown this for $C$. virginica. Investigators using indirect estimates of pollinator importance have also pointed out the varied contributions of different pollinator species or groups to plants living in a variety of habitats. For example, Cruden's (1972) study of three related species of Nemophila (Hydrophyllaceae), Ehrenfeld's (1979) study of several species of Euphorbia, subgenus Chamaesyce (Euphorbiaceae), and Linsey's (1979) study of Zizia trifoliata (Apiaceae) each indicated that oligolectic, andrenid bees were the primary pollinators, but each of the studies also included at least one site with "alternative" primary pollinators. These included polylectic megachilid bees or March flies on Nemophila, bombyliid and tachinid flies on Euphorbia, and syrphid flies on Zizia.

Besides possessing easily accessible flowers, $C$. virginica also exemplifies several other characters that enhance the likelihood of pollination. Flowers produce nectar in both the staminate and pistillate stages, a trait important in attracting generalist foragers like $B$. major. As ovule number per flower is low, insects that carry relatively few pollen grains may still be able to fertilize as many of a flower's ovules as insects that carry many more grains. Increased floral persistence in the absence of fertilization is especially important to reproductive success in a habitat where erratic weather may limit pollinator activity. The value of this trait to $C$. virginica is well illustrated by flowers that bloomed during a 2-d rainy spell in 1979. Of 30 flowers that first became pistillate on those days, 17 remained receptive until a third, sunny day and 14 of these set seed. Of the 13 flowers that were pistillate only during the two rainy days, just 4 set seed.

\section{Role of specialist and generalist pollinators}

A surprising outcome of our study was the nearly equivalent effectiveness of $B$. major and the monolectic $A$. erigeniae as pollinators of $C$. virginica. Based on its hovering mode of feeding and minimal contact with the flower's reproductive parts, we had expected B. major to be a much less effective pollinator than was subsequently indicated by our measurements. Although it visits many other plant species in the community, $B$. major nevertheless visits $C$. virginica at a frequency two-thirds as high as the specialist $A$. eri- geniae females. Because the two insects are equally effective pollinators, $B$. major therefore contributes about two-thirds as much as $A$. erigeniae to $C$. virginica seed set. With our estimate of pollination effectiveness calculated without regard to visit sequence $(P=.64$, Fig. 1) and our previously determined estimate of the mean visitation rate $(2.1$ fly visits. receptive flower ${ }^{-1} \cdot \mathrm{d}^{-1}$ ) the probability that a flower would be successfully pollinated by $B$. major in the absence of any other visitors is 0.76 . Thus $B$. major alone has the potential to pollinate three quarters of the $C$. virginica flowers. Clearly in our North Carolina population $C$. virginica is not solely dependent on the specialist $A$. erigeniae for its pollination success.

Although $A$. erigeniae females and B. major contribute similarly to seed set, they may differ in several aspects related to ability to transfer pollen to conspecific stigmas, including pollen carry-over and flight distance. The number of ovules fertilized by the pollen from a given flower may be affected by the pollen carry-over of the visitors. Pollen carry-over is the percentage of a pollen load picked up from a staminatestage flower that is deposited on each subsequently visited receptive flower (Levin and Kerster 1969). Table 3 , which lists pollination success in terms of the kind of flower last visited before arrival on a receptive flower, provides a functional description of pollen carry-over. Andrena erigeniae females are significantly better pollinators than $B$. major in sequential visits to pistillate flowers $\left(p_{2}>p_{4}\right.$ in Table 3$)$, a consequence of the far greater amount of pollen they carry and the lower proportion of pistillate to staminate flowers in their foraging trips. Most of the pollen that B. major carries is deposited during its first visit to a receptive flower. In our population B. major apparently visits enough staminate flowers that its pollination effectiveness is unimpaired, as indicated by the 0.64 success probability (Fig. 1), which was calculated without regard to visit sequence. However, its low pollen carryover may still reduce gene flow and outcrossing.

The distribution of distances over which pollen is dispersed is a function of both pollinator flight distances and pollen carry-over. In addition to lower pollen carry-over, $B$. major typically has shorter interfloral flight distances than solitary bees, including $A$. erigeniae (Beattie and Culver 1979, A. F. Motten et al., personal observations). Pollen dispersal is more important than seed dispersal in determining neighborhood size in Viola (Beattie and Culver 1979) and probably in $C$. virginica as well. The frequent tendency of $B$. major to visit adjacent flowers may further increase inbreeding, as $C$. virginica corms can produce several racemes making nearby flowers genetically identical. Although $C$. virginica is largely selfcompatible, Schemske's (1977) hand-pollinations and our own greenhouse observations suggest that self- 
pollinated flowers are slightly less fertile than outcrossed ones.

Size of the pollen load may have a greater impact on seed quality than seed quantity. Bombylius major carries few pollen grains, mostly on the head and legs, whereas $A$. erigeniae females visiting $C$. virginica are generally coated with pollen grains over their ventral surface. Flowers successfully fertilized with relatively few pollen grains after a $B$. major visit may produce seed that is inferior to that of flowers more extensively pollinated by $A$. erigeniae. In commercially grown carrots, plants with high pollination levels produce seed with a greater percent germination that do inadequately pollinated plants (Hawthorne et al. 1956). Larger stigma pollen deposits may also increase pollen tube competition, an interaction that Mulcahy and Mulcahy (1975) have related experimentally to increased offspring vigor.

Low pollen carry-over by a pollinator visiting more than one plant species can also reduce pollination effectiveness if pollen picked up from one species is lost during subsequent visits to the other species. Such interference competition among plants sharing a common pollinator may also involve stigma contamination with loads of foreign pollen (Waser 1978, Brown and Kodric-Brown 1979). Neither effect is likely with $C$. virginica, which usually grows in dense stands with scattered individuals of other species interspersed. Most pollinator visit sequences are intraspecific, even for an extreme generalist like B. major. Thus pollinator inconstancy has little effect on seed set in $C$. virginica populations. In contrast, less abundant, intermingled plant species could experience competition if they share pollinators with $C$. virginica. At present we are studying one of these species, Stellaria pubera Michaux (Caryophyllaceae), to determine how it is affected by sharing its primary pollinators, B. major and Nomada, with $C$. virginica.

\section{AcKNowledgments}

We thank Henry Wilbur, Janis Antonovics, Mark Rausher, Donald Stone, and two anonymous reviewers for their helpful suggestions on the manuscript. Donald Burdick provided valuable statistical advice on evaluation of the probability model. We are grateful to the following individuals for their insect identifications: Wallace LaBerge (Andrenidae), George Eickwort (Halictidae) and Ken Ahlstrom (Tachinidae).

\section{Literature Cited}

Adlerz, W. C. 1966. Honey-bee visit numbers and watermelon pollination. Journal of Economic Entomology 59:28-30.

Anderson, E., and L. Hubricht. 1940. A method for describing and comparing blooming-seasons. Bulletin of the Torrey Botanical Club 67:639-648.

$\rightarrow$ Baker, H. G., and P. D. Hurd. 1968. Intrafloral ecology. Annual Review of Entomology 13:385-414.

Beattie, A. J. 1971. Pollination mechanisms in Viola. New Phytologist 70:343-360.

. 1972. The pollination ecology of Viola. 2; pollen loads of insect-visitors. Watsonia 9:13-25.
Beattie, A. J., and P. C. Culver. 1979. Neighborhood size in Viola. Evolution 33:1226-1229.

Bohart, G. E., and W. P. Nye. 1960. Insect pollinators of carrots in Utah. Bulletin 419, Utah Agricultural Experimental Station, Logan, Utah, USA.

Bornkamm, R. 1975. A vegetation map of the Henry J. Oosting Natural Area, Orange County, North Carolina. Technical Bulletin Number 3, Duke University of School of Forestry and Environmental Studies, Durham, North Carolina, USA.

Brown, J., and A. Kodric-Brown. 1979. Convergence, competition, and mimicry in a temperate community of hummingbird-pollinated flowers. Ecology 60:1022-1035.

Cruden, R. W. 1972. Pollination biology of Nemophila menziesii (Hydrophyllaceae) with comments on the evolution of oligolectic bees. Evolution 26:373-389.

Damm, H. C., editor. 1966. Methods and references in biochemistry and biophysics. World Publishing, Cleveland, Ohio, USA.

Davis, R. L., Jr., and W. E. LaBerge. 1975. The nest biology of the bee Andrena (Ptilandrena) erigeniae Robertson (Hymenoptera: Andrenidae). Biological Notes Number 95, Illinois Natural History Survey, Champaign, Illinois, USA.

Ehrenfeld, J. G. 1979. Pollination of three species of Euphorbia subgenus Chamaesyce, with special reference to bees. American Midland Naturalist 101:87-98.

Grant, V. 1948. Pollination systems as isolating mechanisms in angiosperms. Evolution 3:82-97.

Grant, V., and K. Grant. 1965. Flower pollination in the Phlox family. Columbia University Press, New York, New York, USA.

Hawthorne, L. R., G. E. Bohart, and E. H. Toole. 1956. Carrot seed yield and germination as affected by different levels of insect pollination. Proceedings of the American Society for Horticultural Science 67:384-389.

Heinrich, B., and P. Raven. 1972. Energetics and pollination ecology. Science 176:597-602.

Kevan, P. G. 1972. Insect pollination of high arctic flowers. Journal of Ecology 60:831-847.

Levin, D., and D. Berube. 1972. Phlox and Colias: the efficiency of a pollination system. Evolution 26:242-250.

Levin, D., and H. Kerster. 1969. The dependence of beemediated pollen and gene dispersal upon plant density. Evolution 23:560-571.

Lewis, W. H., and J. C. Semple. 1977. Geography of Claytonia virginica cytotypes. American Journal of Botany 64: 1078-1082.

Linsey, A. H. 1979. Pollination in Thaspium and Zizia. Dissertation. University of North Carolina, Chapel Hill, North Carolina, USA.

Lovell, H. B. 1942. The life story of three spring wildflowers. Wild Flower 19:60-65.

Macior, L. W. 1967. Pollen-foraging behavior of Bombus in relation to pollination of nototribic flowers. American Journal of Botany 54:359-364.

Mood, A. M., F. G. Graybill, and D. C. Boes. 1974. Introduction to the theory of statistics. Third edition. McGrawHill, New York, New York, USA.

Mulcahy, D. L., and G. B. Mulcahy. 1975. The influence of gametophytic competition on sporophytic quality in Dianthus chinensis. Theoretical and Applied Genetics 46:277280.

Ornduff, R. 1975. Complementary roles of halictids and syrphids in the pollination of Jepsonia heterandra (Saxifragaceae). Evolution 29:371-373.

Parks, C. R., and J. W. Hardin. 1963. Yellow Erythroniums of the eastern United States. Brittonia 15:245-259.

$\rightarrow$ Primack, R. B., and J. A. Silander. 1975. Measuring the relative importance of different pollinators to plants. Nature 255: 143-144. 
$\rightarrow$ Primack, R. B., and J. A. Silander. 1978. Pollination intensity and seed set in the evening primrose (Oenothera fruticosa). American Midland Naturalist 100:213-216.

Radford, A. E., H. E. Ahles, and C. R. Bell. 1968. Manual of the vascular flora of the Carolinas. University of North Carolina Press, Chapel Hill, North Carolina, USA.

$\rightarrow$ Reader, R. J. 1975. Competitive relationships of some bog ericads for major insect pollinators. Canadian Journal of Botany 53:1300-1305.

Robertson, C. 1929. Flowers and insects. Science Press, Lancaster, Pennsylvania, USA.

1930. Proterandry and the flight of bees. III (Hym.: Apoidea). Entomological News 41:331-336.

Schemske, D. W. 1977. Flowering phenology and seed set in Claytonia virginica (Portulacaceae). Bulletin of the Torrey Botanical Club 104:254-263.

Schemske, D. W., M. F. Willson, M. N. Melampy, L. J. Miller, L. Verner, K. M. Schemske, and L. B. Best. 1978. Flowering ecology of some spring woodland herbs. Ecology 59:351-366.

Waser, N. M. 1978. Competition for pollination and sequential flowering in two Colorado wildflowers. Ecology 59:934-944.

$\longrightarrow \rightarrow-$ 1979. Pollinator availability as a determinant of flowering time in Ocotillo (Fasquieria splendens). Oecologia 39:107-121.

Zimmerman, M. 1980. Reproduction in Polemonium: competition for pollinators. Ecology 61:497-501. 